\title{
PREVENÇÃO DA COVID-19? EFEITOS ADVERSOS DA IVERMECTINA EM POSOLOGIA INAPROPRIADA
}

\section{ARTIGO DE REVISÃO}

PEREIRA, Fernanda Cândido ${ }^{1}$

MONTENEGRO, Mariana Lima ${ }^{2}$

BARBÉRO, Bruna Benedetti ${ }^{3}$

PARENTE, Débora Barbosa da Silva ${ }^{4}$

ARANTES, Isabela Maria ${ }^{5}$

ZOOBI, João Luís de Arruda Pereira ${ }^{6}$

FROTA, Mateus Gomes ${ }^{7}$

SANTOS, Rafael Lucas Simões dos ${ }^{8}$

CUNHA, Rafaela de Albuquerque ${ }^{9}$

${ }^{1}$ Discente do curso de Medicina do Centro Universitário UNINTA, Sobral - CE.

2 Orientadora. Médica residente em Clínica Médica.

${ }^{3}$ Discente do curso de Medicina da Universidade São Caetano do Sul.

${ }^{4}$ Discente do curso de Medicina do Centro Universitário UNINTA, Sobral - CE.

${ }^{5}$ Discente do curso de Medicina da Universidade de Cuiabá.

${ }^{6}$ Discente do curso de Medicina da Universidade Católica de Pernambuco.

7 Discente do curso de Medicina do Centro Universitário UNINTA, Sobral - CE.

${ }^{8}$ Discente do curso de Medicina da Universidade Federal do Ceará, Sobral - CE.

${ }^{9}$ Discente do curso de Medicina do Centro Universitário UNINTA, Sobral - CE. 


\section{LIMA, Andreza Brandão Theophilo ${ }^{10}$}

\section{PEREIRA, Fernanda Cândido. Et al. Prevenção da COVID-19? Efeitos adversos da} ivermectina em posologia inapropriada. Revista Científica Multidisciplinar Núcleo do Conhecimento. Ano 05, Ed. 10, Vol. 05, pp. 129-148. Outubro de 2020. ISSN: 24480959, Link de acesso: https://www.nucleodoconhecimento.com.br/saude/posologiainapropriada

\section{RESUMO}

Objetivo: Identificar os malefícios e a toxicidade do uso da ivermectina em doses maiores do que as doses terapêuticas, bem como correlacionar seu uso, em doses mais elevadas do que as terapêuticas convencionais, como forma de prevenção para a COVID-19. Métodos: Trata-se de uma revisão bibliográfica do tipo integrativa, com abordagem qualitativa e natureza aplicada, objetivando a descrição da análise de dados coletados sobre o uso inapropriado da Ivermectina no tratamento da COVID19 e seus efeitos adversos. Este trabalho foi desenvolvido através de pesquisa bibliográfica na base de dados da Biblioteca Virtual de Saúde (BVS) e do PubMed, na qual foram priorizados artigos/estudos publicados nos últimos 5 anos, que retratassem temática convergente aos objetivos da pesquisa, anexados nos idiomas: português, inglês e espanhol. Desse modo, foram selecionados 17 artigos para leitura, os quais constituem esta revisão de literatura. Resultados: $25,52 \%$ dos estudos selecionados abordaram os principais efeitos adversos advindos da terapia convencional com Ivermectina, os quais, em sua maioria, são sintomas gástricos e neurológicos leves, como náuseas, vômitos, cefaleia e vertigens. Dito isso, observou-se também que em $35,29 \%$ dos estudos analisados indicam o sucesso da Ivermectina em reduzir o material genético viral do SARS-CoV-2, in vitro. Entretanto, ao se considerar o organismo humano a dose utilizada nos estudos in vitro torna-se inviável, pois proporcionalmente seria necessária uma dose de 1000 a 1200mg, logo tal dose aplicada em humanos poderia levar a intoxicação, cujo sintomas são ataxia e convulsões. Dentre os demais sintomas correlacionados ao tratamento com

${ }^{10}$ Discente do curso de Medicina da Universidade Federal do Ceará, Sobral - CE. 
Ivermectina também observou-se a presença de bradipneia, tremores, ptose, redução de atividade e midríase, estes em doses acima da convencional. Conclusão: Diante dos estudos sobre a eficácia da Ivermectina como prevenção e resolução da COVID19 e dos estudos que relatam sua toxicidade e malefícios em altas doses, pode-se concluir que ainda não há confirmação de eficácia do seu uso em humanos para tratamento e prevenção antiviral.

Palavras-Chave: Covid-19, coronavírus, ivermectina, prevenção, efeitos Adversos.

\section{INTRODUÇÃO}

A ivermectina é um medicamento antiparasitário de amplo espectro, derivado das avermectinas, que possui efeitos adversos leves e transitórias, podendo ocorrer náusea, vômitos, diarreia, astenia, dor abdominal, anorexia, constipação, tontura, sonolência, vertigem, tremor, prurido, erupções e urticária. (ANVISA, 2016). A ivermectina é considerada relativamente segura, não apresentando genotoxicidade; porém em uma dose muito alta, causou embriotoxicidade em animais. Edwards, demonstrou que a toxicidade, apesar de ser rara, pode ser devida à overdose aguda ou crônica do medicamento.

Quanto a seu efeito antiviral, esta droga demonstrou potencial de ação in vitro para alguns tipos de vírus, no entanto, não houve desfechos semelhantes em seres humanos, como é o caso dos estudos realizados com a dengue, HIV, Influenza e Zika vírus. (YAVUZ et al., 2020; PATRÌ et al., 2020; RODON et al., 2020)

Com respeito ao efeito antiviral da ivermectina contra SARS-CoV-2, estudos demonstram que proteínas desse vírus tem um papel importante na IMPa/ $\beta 1$ durante a infecção da célula hospedeira (ROWLAND et al., 2005; TIMANI et al., 2005; WULAN et al., 2015), que podem ter impacto na divisão dessa célula pelo vírus. (HISCOX et al., 2001; WURM et al., 2001). Além disso, a proteína ORF6, presente no vírus, demonstrou antagonizar a atividade antiviral do fator de transcrição STAT, sequestrando IMPa/ $\beta$ (FRIEMAN et al., 2007). Esses relatórios sugeriram que a 
atividade inibitória do transporte nuclear da ivermectina pode ser eficaz contra a SARS-CoV-2.

Estudos In Vitro são os primeiros passos para a criação de novas medicações. Mas nem sempre os resultados conseguidos in vitro obtém êxito in vivo, e o processo deve ser bem documentado e estuda a fim de se evitar conclusões danosas.

Embora a Ivermectina seja considerada relativamente segura, em dose terapêutica adequada e orientada pelo profissional de saúde, a dose utilizada experimento In vitro foi de $5 \mu \mathrm{M}$ e para atingir essa dose em humanos, via oral seria necessária de 1000$1200 \mathrm{mg}$ de Ivermectina, de acordo com a ficha técnica desse medicamento, destacando assim a preocupação com efeitos adversos graves, produzindo regimes de dosagem de overdose. (CALY et al., 2020)

Este trabalho pretende, portanto, identificar os efeitos do uso indiscriminado de Ivermectina como prevenção e resolução da COVID-19, bem como avaliar os riscos e implicações médicas e sociais da automedicação.

\section{DESENVOLVIMENTO}

\subsection{METODOLOGIA}

O artigo em questão consiste em uma revisão bibliográfica do tipo integrativa, de abordagem qualitativa e natureza aplicada, objetivando a descrição da análise de dados coletados sobre o uso inapropriado da Ivermectina no tratamento da COVID19 e seus efeitos adversos.

As bases de dados utilizadas na busca dos artigos foram a Biblioteca Virtual de Saúde (BVS) e o PubMed, a qual foi realizada no mês de agosto de 2020. Para isso, foram utilizados descritores contidos no DeCS (Descritores em Ciências da Saúde), relacionados à temática da pesquisa e referentes aos termos: "Ivermectina", "COVID19" e "tratamento farmacológico". Para refinar a pesquisa, os descritores foram empregados em inglês, português e espanhol, adicionando-se operadores booleanos (parênteses, "AND" e "OR"), que juntos permitiram a elaboração da fórmula de 
pesquisa. Nessa sequência, foram aplicados filtros de pesquisa, como texto completo disponível, recorte temporal dos últimos 5 anos e idioma espanhol, inglês e português.

Nessa perspectiva, com o intuito de aperfeiçoar os resultados, traçou-se critérios de elegibilidade, tendo como critérios de inclusão: artigos que retratassem temática convergente aos objetivos da pesquisa, escritos em português, inglês e espanhol, indexados na base de dados nos últimos 5 anos, estando disponíveis na íntegra. Ademais, os critérios de exclusão descartaram artigos não disponíveis na íntegra e os que não atendiam à finalidade da pesquisa e artigos duplicados.

Durante a busca, foram encontrados 12 artigos relacionados no PubMed e 65 artigos na BVS, sendo selecionados 17 artigos, a partir da leitura do título, dos resumos e da leitura dinâmica dos textos, por parte dos pesquisadores. Dessa forma, das referências selecionadas, 1 está presente no PubMed e 16 na BVS.

Dessa forma, ressaltamos que, por ser apenas uma revisão de literatura e por não haver caráter prático, não há a necessidade de submissão ao Comitê de Ética em Pesquisa (CEP).

Para melhor organização dos resultados de pesquisa, os artigos encontrados foram alocados em quadro, organizado em ordem alfabética, contendo informações como: título do artigo, autores e ano de publicação, país e principais resultados, todos relacionados aos efeitos adversos e toxicidade do uso inadequado da Ivermectina, sobretudo no contexto da COVID-19.

\subsection{RESULTADOS}

Tabela 1 - Principais resultados.

\begin{tabular}{|l|l|l|l|}
\hline Título & $\begin{array}{l}\text { Autor/Ano de } \\
\text { publicação }\end{array}$ & País & Principais resultados \\
\hline Kit-COVID & Lima et al. 2020 & Brasil & $\begin{array}{l}\text { Não foram encontrados } \\
\text { estudos que comprovassem }\end{array}$ \\
\hline
\end{tabular}




\begin{tabular}{|c|c|c|c|}
\hline & & & $\begin{array}{l}\text { segurança no uso de } \\
\text { Ivermectina em doses } \\
\text { maiores que a terapêutica, } \\
\text { ou repetição da dose em } \\
\text { tempo inferior ao mínimo } \\
\text { previsto ( } 3 \text { meses), além de } \\
\text { ter sido relatado que, tanto } \\
\text { em doses terapêuticas (até } \\
800 \text { mcg/kg), como em } \\
\text { doses excessivas (acima de } \\
2000 \text { mcg/kg), não se foi } \\
\text { possível atingir } \\
\text { concentrações capazes de } \\
\text { inibir a replicação do SARS- } \\
\text { CoV-2. }\end{array}$ \\
\hline $\begin{array}{l}\text { The Battle against } \\
\text { COVID } 19 \text { Pandemic: } \\
\text { What we Need to } \\
\text { Know Before we } \\
\text { "Test Fire" Ivermectin }\end{array}$ & $\begin{array}{l}\text { Banerjee et al. } \\
2020\end{array}$ & Índia & $\begin{array}{l}\text { Há evidência da eficácia do } \\
\text { uso da ivermectina no } \\
\text { tratamento in vitro de } \\
\text { diversas doenças causadas } \\
\text { por vírus de RNA e DNA. } \\
\text { Além disso, no estudo dos } \\
\text { pesquisadores australianos, } \\
\text { Caly et al, ficou evidente a } \\
\text { eficácia da ivermectina na } \\
\text { sua atividade inibitória nas } \\
\text { linhas de células } \\
\text { transfectadas pelo vírus } \\
\text { SARS-Cov-2, utilizando uma } \\
\text { concentração de } 5 \mu \mathrm{M} \text {. }\end{array}$ \\
\hline
\end{tabular}




\begin{tabular}{|c|c|c|c|}
\hline $\begin{array}{l}\text { Informe diário de } \\
\text { evidências - COVID- } \\
19 \text { №26 }\end{array}$ & $\begin{array}{l}\text { Ministério da } \\
\text { Saúde, } 2020 .\end{array}$ & Brasil & $\begin{array}{l}\text { O estudo in vitro de Carly et } \\
\text { al (2020) identificou } \\
\text { atividade antiviral } \\
\text { significativa pela } \\
\text { Ivermectina em relação ao } \\
\text { SARS-CoV-2 em } 48 \mathrm{~h} \\
\text { (redução de } 99,8 \% \text { do RNA } \\
\text { viral), entretanto os outros } 4 \\
\text { estudos clínicos in vivo } \\
\text { ainda estão em andamento. }\end{array}$ \\
\hline $\begin{array}{l}\text { Recommendation } \\
\text { Regarding the Use of } \\
\text { Ivermectin as a } \\
\text { Treatment } \\
\text { COVID-19 }\end{array}$ & $\begin{array}{l}\text { Pan American } \\
\text { Health } \\
\text { Organization, } \\
2020 .\end{array}$ & $\begin{array}{l}\text { Americas } \\
\text { (todos os } \\
\text { países) }\end{array}$ & $\begin{array}{l}\text { Falta de resultados e } \\
\text { evidências científicas que } \\
\text { comprovem a eficácia da } \\
\text { ivermectina no tratamento } \\
\text { da COVID-19. Além disso, } \\
\text { evidenciou que as dosagens } \\
\text { utilizadas nos estudos in } \\
\text { vitro são muito além da } \\
\text { aprovada pelo FDA (U.S } \\
\text { Food and Drug } \\
\text { Administration) para o } \\
\text { tratamento de doenças } \\
\text { parasitárias. }\end{array}$ \\
\hline $\begin{array}{l}\text { Informe diário de } \\
\text { evidências - COVID- } \\
19 \text { № } 45\end{array}$ & $\begin{array}{l}\text { Ministério da } \\
\text { Saúde, } 2020 .\end{array}$ & Brasil & $\begin{array}{l}\text { Evidências limitadas em } \\
\text { relação ao uso de } \\
\text { ivermectina no tratamento } \\
\text { de pacientes com covID- } \\
19 \text {, com } 7 \text { ensaios clínicos } \\
\text { em andamento, um estudo } \\
\text { observacional que } \\
\text { evidenciou diminuição da }\end{array}$ \\
\hline
\end{tabular}




\begin{tabular}{|c|c|c|c|}
\hline & & & $\begin{array}{l}\text { mortalidade global nos } \\
\text { pacientes que receberam } \\
\text { ivermectina } 159 \mathrm{mcg} / \mathrm{kg} \text { em } \\
\text { relação aos que não } \\
\text { receberam ( } 1,4 \% \text { vs } 8,5 \%) ; \\
\text { e } 2 \text { comunicados do FDA } \\
\text { alertando sobre os riscos da } \\
\text { automedicação e danos em } \\
\text { casos de uso da ivermectina } \\
\text { com formulações para } \\
\text { animais. }\end{array}$ \\
\hline $\begin{array}{l}\text { lvermectina } \quad \text { para } \\
\text { Covid-19. Revisão } \\
\text { sistemática rápida }\end{array}$ & $\begin{array}{l}\text { Marra et al., } \\
2020\end{array}$ & Brasil & $\begin{array}{l}\text { Ivermectina diminuiu } 93 \% \text { do } \\
\text { material genético do SARS- } \\
\text { CoV-2 em } 24 \text { horas e, em } 48 \\
\text { horas, houve uma } \\
\text { diminuição de } 99,8 \% \text { do } \\
\text { material genético. Portanto, } \\
\text { não ficou comprovada a } \\
\text { eficácia do uso da } \\
\text { ivermectina em humanos, } \\
\text { ficando dependente de } \\
\text { resultados de estudos em } \\
\text { humanos. }\end{array}$ \\
\hline $\begin{array}{l}\text { Uso de ivermectina } \\
\text { para el tratamiento } \\
\text { de pacientes adultos } \\
\text { con COVID-19 } \\
\text { Version } 2\end{array}$ & $\begin{array}{lr}\text { Instituto de } & \text { de } \\
\text { Evaluacion de } & \text { de } \\
\text { Tecnologias } & \text { en } \\
\text { Salud } & \text { e } \\
\text { Investigación, } & \\
2020 . & \end{array}$ & Peru & $\begin{array}{l}\text { Até o momento, não há } \\
\text { evidência de benefício } \\
\text { clínico do uso de } \\
\text { Ivermectina em pacientes } \\
\text { afetados pelo vírus Sars- } \\
\text { CoV-2. }\end{array}$ \\
\hline $\begin{array}{l}\text { COVID-19 } \quad \text { y } \\
\text { Argumentum } \quad \text { ad }\end{array}$ & $\begin{array}{l}\text { Lopez et al. } \\
2020 .\end{array}$ & Espanha & $\begin{array}{l}\text { Exposição da crença por } \\
\text { parcela da sociedade de que }\end{array}$ \\
\hline
\end{tabular}




\begin{tabular}{|c|c|c|c|}
\hline $\begin{array}{l}\text { ignorantiam } 0 \ll \text { no } \\
\text { todo vale» }\end{array}$ & & & $\begin{array}{l}\text { o desconhecimento de } \\
\text { provas contra a ideia suas } \\
\text { ideias conta como uma } \\
\text { evidência a seu favor, } \\
\text { ficando mais claro durante a } \\
\text { atual pandemia. Falta de } \\
\text { estudos clínicos que } \\
\text { comprovem a eficácia da } \\
\text { ivermectina no tratamento } \\
\text { da coviD-19, existindo } \\
\text { somente estudo in vitro que } \\
\text { utiliza concentrações muito } \\
\text { superiores ao utilizados por } \\
\text { humanos. }\end{array}$ \\
\hline $\begin{array}{l}\text { Prevalence and } \\
\text { alternative treatment } \\
\text { of Head-Lice } \\
\text { infestation in rural } \\
\text { Thailand: } \\
\text { community-based } \\
\text { study }\end{array}$ & $\begin{array}{l}\text { Singhasivanon } \\
\text { et al. } 2019 .\end{array}$ & Korea & $\begin{array}{l}\text { O uso de ivermectina } 200 \\
\mathrm{mcg} / \mathrm{kg} \text {, uma vez por } \\
\text { semana, durante duas } \\
\text { semanas, mostrou-se } \\
\text { devidamente seguro e } \\
\text { eficiente para o tratamento } \\
\text { de piolho, sendo o principal } \\
\text { efeito adverso relatado a dor } \\
\text { de cabeça. }\end{array}$ \\
\hline $\begin{array}{l}\text { Wonder drug for } \\
\text { worms: A review of } \\
\text { three decades of } \\
\text { ivermectin use in } \\
\text { dermatology }\end{array}$ & $\begin{array}{l}\text { Gowtham et al. } \\
2019 .\end{array}$ & Índia & $\begin{array}{l}\text { A ivermectina é eficaz no } \\
\text { tratamento de diversas } \\
\text { doenças dermatológicas e } \\
\text { raramente causa efeitos } \\
\text { adversos no paciente. Além } \\
\text { disso, é considerada } \\
\text { relativamente segura mas, } \\
\text { em uma dose muito alta, }\end{array}$ \\
\hline
\end{tabular}




\begin{tabular}{|c|c|c|c|}
\hline & & & $\begin{array}{lr}\text { demonstrou } & \text { causar } \\
\text { embriotoxicidade } & \mathrm{em} \\
\text { animais. } & \end{array}$ \\
\hline $\begin{array}{l}\text { Ivermectin: From } \\
\text { theory to clinical } \\
\text { application }\end{array}$ & $\begin{array}{l}\text { Ashour et al. } \\
2019 .\end{array}$ & Egito & $\begin{array}{l}\text { Evidência de vasta } \\
\text { quantidade de doenças } \\
\text { parasitárias com benefício } \\
\text { de tratamento com } \\
\text { Ivermectina. Também ficou } \\
\text { evidenciado que a } \\
\text { medicação não traz efeitos } \\
\text { colaterais severos, mas } \\
\text { pode ocasionar cefaleias, } \\
\text { vertigem, náuseas ou } \\
\text { diarreia. }\end{array}$ \\
\hline $\begin{array}{l}\text { Population } \\
\text { pharmacokinetics of } \\
\text { oral ivermectin in } \\
\text { venous plasma and } \\
\text { dried blood spots in } \\
\text { healthy volunteers }\end{array}$ & $\begin{array}{l}\text { Duthaler et al. } \\
2019 .\end{array}$ & Índia & $\begin{array}{l}\text { As características } \\
\text { farmacocinéticas da } \\
\text { ivermectina oral são } \\
\text { influenciadas diretamente } \\
\text { pelo peso dos pacientes }\end{array}$ \\
\hline $\begin{array}{l}\text { Serious neurological } \\
\text { adverse events after } \\
\text { Ivermectin-Do they } \\
\text { occur beyond the } \\
\text { indication of } \\
\text { Onchocerciasis? }\end{array}$ & $\begin{array}{l}\text { E. Chandler et } \\
\text { al. } 2018 .\end{array}$ & EUA & $\begin{array}{l}\text { Efeitos neurológicos } \\
\text { relacionados à ivermectina } \\
\text { são, mais comumente, dor } \\
\begin{array}{l}\text { de cabeça e tontura. Porém, } \\
\text { pode haver efeitos } \\
\text { neurológicos graves } \\
\text { (relacionados, } \\
\text { principalmente, } \\
\text { interações } \\
\text { medicamentosas, que }\end{array}\end{array}$ \\
\hline
\end{tabular}




\begin{tabular}{|c|c|c|c|}
\hline & & & $\begin{array}{l}\text { devem ser sempre } \\
\text { investigadas). }\end{array}$ \\
\hline $\begin{array}{ll}\text { Propiedades } & \\
\text { antivirales } & y \\
\text { antiinflamatorias } & \text { de } \\
\text { ivermectina y su } \\
\text { potencial uso en } \\
\text { CoVID-19 }\end{array}$ & $\begin{array}{l}\text { Portmann- } \\
\text { Baracco et al. } \\
2020 .\end{array}$ & Espanha & $\begin{array}{l}\text { Os efeitos antivirais só foram } \\
\text { demonstrados in vitro, } \\
\text { entretanto as atividades anti- } \\
\text { inflamatórias foram } \\
\text { evidenciadas in vitro e in } \\
\text { vivo, tendo, a ivermectina, } \\
\text { propriedades anti- } \\
\text { inflamatórias não só a nível } \\
\text { sistêmico, como também a } \\
\text { nível pulmonar, reduzindo a } \\
\text { hipersecreção de muco e a } \\
\text { produção de citocinas nos } \\
\text { segmentos } \\
\text { broncoalveolares. }\end{array}$ \\
\hline $\begin{array}{l}\text { Uso de ivermectina } \\
\text { para el tratamiento } \\
\text { de pacientes adultos } \\
\text { con COVID-19 }\end{array}$ & $\begin{array}{lr}\text { Instituto de } \\
\text { Evaluacion de } \\
\text { Tecnologias en } \\
\text { Salud } \\
\text { Investigación, } \\
2020 .\end{array}$ & Peru & $\begin{array}{l}\text { Embora não tenha evidência } \\
\text { de algum benefício clínico } \\
\text { da ivermetina no tratamento } \\
\text { da COVID-19, foi constatado } \\
\text { em um estudo in vitro de } \\
\text { Carly et al. (2020) a } \\
\text { obtenção de sucesso na } \\
\text { atividade antiviral contra o } \\
\text { vírus SARS-Cov-2. }\end{array}$ \\
\hline $\begin{array}{l}\text { Ivermectina para } \\
\text { COVID-19 }\end{array}$ & $\begin{array}{l}\text { Instituto de } \\
\text { efectividad } \\
\text { clinica y } \\
\text { sanitaria, 2020 }\end{array}$ & Argentina & $\begin{array}{l}\text { Redução significativa da } \\
\text { mortalidade no grupo de } \\
\text { pacientes que necessitavam } \\
\text { de oxigênio suplementar, em } \\
\text { altas concentrações, e que } \\
\text { utilizaram ivermectina. }\end{array}$ \\
\hline
\end{tabular}




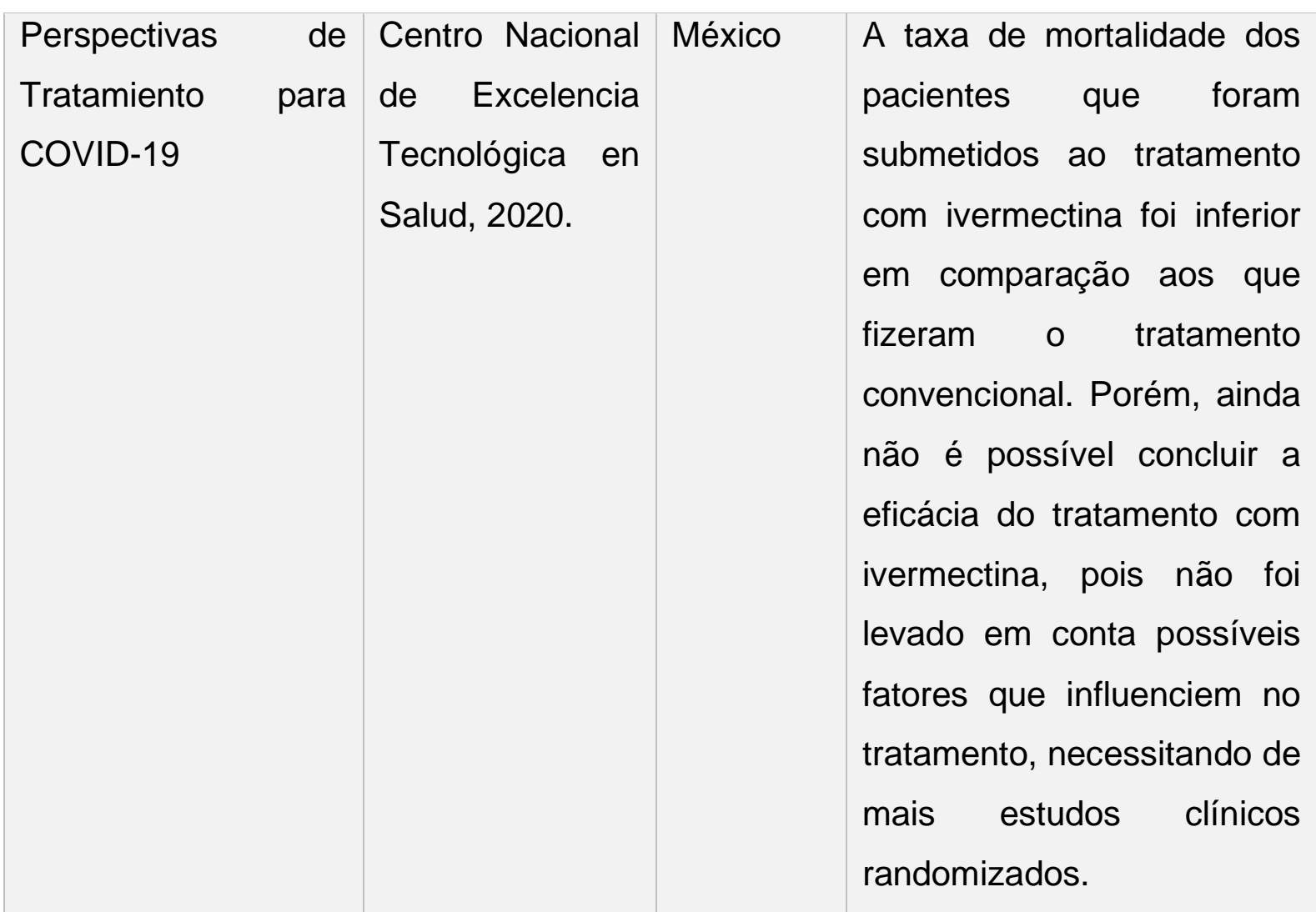

Fonte: Próprio autor.

Dentre os estudos analisados, 35,29\% ( $n=6)$ abordaram o sucesso do estudo in vitro de Carly et al. (2020) com ivermectina, que reduziu o material genético do SARS-CoV2. Com tal estudo, foi possível observar a diminuição do material genético viral em 93\% após as primeiras 24 horas, e depois das 48 horas iniciais foi constatado que o material genético teve uma diminuição de 99,8\% (MARRA et al., 2020). Porém, é inviável alcançar no organismo humano a mesma concentração $(5 \mu \mathrm{M})$ de ivermectina usada no estudo in vitro de Carly et al. (2020), pois seria necessária uma dose de 1000 a $1200 \mathrm{mg}$ do medicamento, ou seja, possivelmente haveria intoxicação, cujos sintomas são ataxia e convulsões (REBOIRO, 2020). Em contrapartida, um relatório brasileiro de Momekov (2020 apud LIMA, 2020) trouxe evidências apontadas por revisão de literatura de que, mesmo em altas dosagens, não foi possível, em seres humanos, atingir a concentração inibitória para o SARS-CoV-2. Portanto, para que a ivermectina tenha sua eficácia comprovada no tratamento da COVID-19, se faz necessário estudos clínicos mais conclusivos que embasem argumentos técnicos 
para sua recomendação (INSTITUTO DE EVALUACIÓN DE TECNOLOGÍAS EN SALUD E INVESTIGACIÓN, 2020).

É válido ressaltar que 2 relatórios incluídos na pesquisa apontaram um estudo de caso-controle de Surgical Outcomes Collaborative (2020 apud CENTRO NACIONAL DE EXCELENCIA TECNOLÓGICA EM SALUD, 2020), envolvendo 1408 pacientes com COVID-19, dos quais $50 \%$ fizeram tratamento com ivermectina $(150 \mathrm{mcg} / \mathrm{kg})$ e $50 \%$, não. Os resultados revelaram uma redução da mortalidade global de aproximadamente $7,1 \%$ no grupo que não recebeu ivermectina, além de uma diminuição de $14 \%$ dos que necessitaram de ventilação mecânica posteriormente, também em relação ao mesmo grupo.

Quanto às demais características da terapêutica com ivermectina, 23,52\% ( $n=4)$ dos estudos selecionados para a base de dados abordaram os principais efeitos adversos advindos dessa terapia. Em revisão narrativa de Ashour et al. (2019), observou-se que os efeitos colaterais relacionados ao uso dessa substância não possuem gravidade importante, sendo, em sua maioria, sintomas gástricos e neurológicos leves, como náuseas, vômitos, dores de cabeça e vertigens, levando em consideração a prescrição habitual da dose única de $200 \mathrm{mcg} / \mathrm{kg}$, a qual pode ser repetida até 1 vez a depender da sua aplicação clínica. Esta evidência é reforçada por um estudo americano de Chandler et al. (2018), que relata efeitos neurológicos de baixa severidade correlacionados ao tratamento com ivermectina. Efeitos estes que podem ser mais intensos (inclusive com alteração do nível de consciência), a depender das interações farmacológicas as quais o paciente está exposto.

\subsection{DISCUSSÃO}

\subsubsection{IVERMECTINA E COVID-19}

A ivermectina é um agente antiparasitário semissintético derivado da avermectina B1, com amplo espectro de atividade e eficaz contra uma séria de parasitoses. Esse medicamento foi estudado durante anos e tem demonstrado atividade antiviral in vitro contra uma ampla gama de vírus de DNA e RNA, como o vírus da imunodeficiência 
humana (HIV), influenza, vírus da dengue e da febre amarela. Porém, essa atividade de limitação da replicação viral não foi demonstrada in vivo, não havendo nenhuma tradução e relevância clínica desses achados (YAVUZ, 2020).

Com o surgimento da pandemia do novo coronavírus foram iniciados vários estudos para investigar um potencial efeito antiviral dessa droga contra o SARS-CoV-2. Carly et al. (2020) demonstraram que, in vitro, este medicamento foi capaz de reduzir o RNA viral em aproximadamente 5000 vezes em 48 horas. Porém é necessário frisar que a dose utilizada foi muito além da permitida pela FDA (Food and Drug Administration) para o uso em seres humanos. Segundo Chaccour (2020), as evidências disponíveis sugerem que os níveis de ivermectina com atividade significativa contra SARS-CoV-2 não seriam alcançados sem aumentos extraordinários e potencialmente tóxicos nos níveis de dosagem de ivermectina em humanos. Portanto, a dose máxima segura pode não ser suficiente contra esse vírus, sendo necessário estudos in vivo e ensaios clínicos para determinar o papel da ivermectina na COVID-19.

A partir do estudo de Carly et al (2020), muitos trabalhos buscaram analisar a eficácia in vivo da ivermectina contra o SARS-CoV-2. Em um estudo de caso-controle de Surgical Outcomes Collaborative (2020 apud CENTRO NACIONAL DE EXCELENCIA TECNOLÓGICA EM SALUD, 2020), foi observada uma redução da mortalidade global e da necessidade de ventilação mecânica em pacientes que utilizaram esse medicamento, mas apresentou muitos vieses, não permitindo conclusões claras acerca da eficácia da ivermectina na infecção pelo novo coronavírus. Em muitos estudos in vivo e ensaios clínicos, foi concluído que os efeitos antivirais da ivermectina ainda não são comprovados e necessitam de mais estudos para saber seus reais benefícios contra o vírus SARS-Cov-2 nos seres humanos. Dessa forma, apesar de estudos in vitro indicarem ação antiviral contra o SARS-Cov-2, o caráter preliminar deste tipo de trabalho não deve corroborar sua utilização clínica.

O estudo de Carly et al. (2020) despertou enorme interesse público e especulações sobre os potenciais efeitos da ivermectina contra o SARS-CoV-2. Assim, o uso disseminado dessa medicação como forma de tratamento e de profilaxia para COVID19 foi popularizado em todo o mundo, mesmo sem haver evidências in vivo e 
comprovação da eficácia dessa droga em ensaios clínicos. Diante de uma pandemia, sem um tratamento efetivo contra o vírus e com grande número de mortos, as pessoas compartilhavam e seguiam fake news, optando pelo uso de medicações, mesmo sem respaldo científico e sem o devido conhecimento dos efeitos adversos e toxicidade. Protocolos de uso da Ivermectina com doses específicas e para diferentes fases da COVID-19 foram promovidas através da mídia. Secretarias municipais de saúde, prefeituras e representantes do poder público recomendavam o uso da ivermectina como medida de profilaxia, defendendo o uso regular para prevenir o risco de infecção e inibir a replicação viral. Pessoas não capacitadas prescreveram métodos de tratamentos e prevenção para um amplo público em redes sociais, homepages farmacêuticos, canais do YouTube e entrevistas na TV. Com isso, a ivermectina se esgotou das drogarias, uma vez que era vendida sem a necessidade de retenção da receita médica. Na tentativa de tentar prevenir a venda desenfreada da droga e reduzir a automedicação, a ANVISA (agência nacional de vigilância sanitária) decidiu inserir a ivermectina na lista de medicamentos de controle especial, sendo vendida somente com receita médica, o que não impediu que as pessoas continuassem a comprar e utilizar a droga segundo os protocolos de profilaxia, prevenção e tratamento de COVID-19 amplamente divulgados (MOLENTO, 2020). Em muitos países o medicamento somente está disponível como soluções injetáveis para uso veterinário, em concentrações muito maiores, e cujo potencial para grave toxicidade em humanos é indiscutível. Na Bulgária, a prática da automedicação com ivermectina para uso veterinário, levou o Sindicato Nacional de Veterinários a divulgar suas preocupações sobre a histeria que esse estudo evocou e a desestimular firmemente essa prática. Em abril, a FDA também compartilhou suas preocupações sobre esta questão e explicitamente desaconselhou quaisquer tentativas de automedicação com ivermectina para COVID-19 (MOMEKOV, 2020). Embora a ivermectina tenha boa margem de segurança, o uso regular dessa medicação pode levar a efeitos adversos e toxicidade importantes. Esse risco também pode ser potencializado por interações medicamentosas ainda não conhecidas, que podem afetar a fisiologia do sistema nervoso central (barreira hematoencefálica) (MOLENTO, 2020). 
Segundo Momekov (2020), atualmente, qualquer tratamento empírico com ivermectina ou sua inclusão em protocolos terapêuticos não são cientificamente justificáveis. Enquanto não houver dados confiáveis de estudos clínicos controlados e sem vieses, a utilização, sobretudo de maneira contínua, da ivermectina para tratamento ou prevenção da COVID-19 deve ser decididamente desencorajada. A Organização Mundial da Saúde (OMS), a Organização PanAmericana da Saúde (OPAS) e a Sociedade Brasileira de Infectologia (SBI) desaconselham fortemente o uso de ivermectina para quaisquer outros propósitos diferentes daqueles devidamente autorizados. A urgência de uma pandemia não anula ou flexibiliza as diretrizes que norteiam a medicina baseada em evidência, caso contrário, pode-se expor a população aos riscos da prescrição e automedicação inadequada. (LIMA et al., 2020).

\subsubsection{CONTRAINDICAÇÕES}

Após a análise dos estudos encontrados, percebeu-se que, com a busca desenfreada por um tratamento eficaz contra A COVID-19, a população está se automedicando, ou seja, não está havendo prescrição e acompanhamento médico, e como consequência observa-se uma pouca preocupação em saber os efeitos e critérios de administração dos medicamentos, entre eles a Ivermectina.

No que se refere às contraindicações ao uso da Ivermectina, é abordado que ela não pode ser administrada em crianças menores de 5 anos ou com peso menor de $15 \mathrm{~kg}$, e em grávidas e mulheres que estão amamentando, até o bebê ter no mínimo 3 meses de vida. Como também em pacientes com meningite ou outras infecções do sistema nervoso central que possam afetar a barreira hematoencefálica (WHO, 1992; NEOQUÍMICA, 2011).

\subsubsection{EFEITOS ADVERSOS}

Os resultados demonstraram que a Ivermectina raramente traz efeitos colaterais severos, mas mesmo nas doses recomendadas pode induzir várias reações indesejadas em diferentes órgãos, como cefaleias, vertigem, náuseas, diarreia, palpitações e hipotensão ortostática. Além disso, foi identificado outros efeitos em 
pacientes, como a hepatite, insônia, convulsão, edema facial e periférico e Síndrome de Stevens-Johnson (LIMA, 2020). É necessário destacar que foram relatadas a exacerbação da asma brônquica em vários países estudados (ASHOUR, 2019). Dessa forma, as reações adversas severas são classificadas como infrequentes (SOLE et al., 1989).

Em um ensaio clínico conduzido na África e América Central, cerca de 50.000 pacientes receberam uma dose de $150 \mu \mathrm{g} / \mathrm{kg}$, que é considerado uma dose crônica, e foram obtidos resultados que demonstraram uma incidência de $9 \%$ de reações. $A$ grande maioria destes eram do tipo Mazzotti, efeitos colaterais associados ao tratamento da oncocercose ou à própria doença, como edema, prurido e erupção cutânea. Bem como tonturas, linfadenite, artralgia, mialgia e irritação ocular resultante da morte súbita de um grande número de microfilárias, mas apenas em $0,25 \%$ dos pacientes foram classificados como graves. (WHO, 1992).

Em um outro ensaio clínico, foram constatadas alterações laboratoriais após o uso da Ivermectina, como eosinofilia transitória, elevação das transaminases e aumento da hemoglobina (SOLE et al., 1989).

Com relação as interações medicamentosas, foi demonstrado em um estudo in vivo que a Ivermectina pode interagir com outras medicações, como por exemplo ela pode aumentar os efeitos farmacológicos do Diazepam, um benzodiazepina de ação calmante. (WHO, 1992)

Evidencia-se, portanto que ao contrário do que vem sendo divulgado nas redes sociais, a Ivermectina não é isenta de riscos mesmo em doses recomendadas e sob prescrição médica. Contudo, restam dúvidas quanto aos efeitos de uma posologia inapropriada e em uso crônico.

\subsubsection{RESISTÊNCIA}

A partir das pesquisas coletadas, não foram encontrados estudos que demonstrassem o surgimento de uma resistência pelo uso da Ivermectina em relação ao COVID-19. 
Contudo, foi encontrado diversos estudos que relataram o uso crônico de ivermectina contra helmintos pode levar ao surgimento de resistência ao medicamento em alguns humanos. No entanto, os mecanismos responsáveis por esta resistência ainda continuam não esclarecidos. A resistência a Ivermectina foi previamente encontrada em animais e poucos ensaios clínicos relataram a manifestação de uma resposta abaixo do esperado ou efeitos negativos posteriores ao uso crônico da medicação (ASHOUR, 2019).

Embora haja evidências para a resistência a Ivermectina em uso contra helmintos, ainda são necessários estudos para compreender o surgimento de uma resistência dessa medicação no tratamento da COVID-19.

\subsubsection{TOXICIDADE}

$\mathrm{Na}$ coleta dos estudos, foi identificado as doses necessárias para cada helmintíase, e que quantidades próximas das doses terapêuticas em animais (100 a $200 \mu \mathrm{g} / \mathrm{kg}$ de peso corporal) não são perigosas para os humanos. Entretanto, a ingestão de grandes quantidades (10 a 100 vezes a dosagem terapêutica em animais) pode produzir sintomas semelhantes aos observados em estudos de toxicologia animal com níveis tóxicos elevados. (WHO, 1992). Vale salientar que mesmo uma dose de ivermectina 10 vezes maior que a aprovada pelo FDA para ser utilizada em humanos, não foi capaz de reproduzir, in vivo, o efeito antiviral contra o SARS-CoV-2 observada no estudo in vitro de Caly et al (2020) (CHACCOUR et al., 2020; MOMEKOK et al., 2020).

Em um estudo clínico acerca de doenças filarióides, foi administrado Ivermectina oral em doses de 2 a $200 \mu \mathrm{g} / \mathrm{kg}$, e observou-se reações adversas que incluíram apenas um evento transitório. Os outros efeitos foram considerados não graves e foram principalmente do tipo esperado com base nas características da doença a serem tratadas (WHO, 1992).

Além dos estudos apresentados, foi realizada uma pesquisa em laboratório que relatou letalidade significativa em ratos após doses únicas de 40 a $50 \mathrm{mg} / \mathrm{Kg}$ de ivermectina. E, não foi observada letalidade significativa em cães após doses únicas 
de até $10 \mathrm{mg} / \mathrm{Kg}$. Nessas dosagens, em seres humanos, observaram-se os seguintes sinais relacionados ao tratamento: ataxia, bradipneia, tremores, ptose, redução de atividade, vômitos e midríase. Entre outros efeitos adversos relatados estão convulsões, ataxia, dispneia, dor abdominal, parestesia e urticária (NEOQUíMICA, 2011).

Em pacientes com um estado hiperinflamatório, como os infectados pelo SARS-CoV2, outros tipos de infecções sistêmicas ou doenças inflamatórias, há um aumento da permeabilidade endotelial da barreira hematoencefálica, podendo levar à passagem de medicamentos potencialmente danosos ao sistema nervoso central (SNC). Desse modo, a ivermectina pode cruzar os canais de cloro bloqueados por GABA presentes no SNC dos mamíferos e causar neurotoxicidade, com depressão do SNC e potencialização dos efeitos dos benzodiazepínicos (CHACCOUR, 2020). Os níveis de anti-SARS-CoV-2 se sobrepõem às concentrações inibitórias de ivermectina na glicoproteína $\mathrm{P}$ e outros transportadores que impedem a penetração da droga no SNC. Overdoses em humanos foram associadas a vômitos, taquicardia e anormalidades no ECG, flutuações significativas da pressão arterial, efeitos no SNC (sonolência, ataxia) e distúrbios visuais (midríase) (MOMEKOV, 2020), diante disso, é necessária cautela no seu uso.

Considerando que as doses da Ivermectina para tratamento das parasitoses são bem menores que a relatada para uma ação antirretroviral eficaz contra o SARS-CoV-2, foi possível constatar que o uso do medicamento causaria mais efeitos tóxicos do que observado nas parasitoses. É necessário que mais estudos sejam realizados para comprovar a segurança no uso de Ivermectina em doses maiores do que a terapêutica.

\section{CONSIDERAÇÕES FINAIS}

Logo, concluímos que os estudos feitos até agora sobre a eficácia da Ivermectina como prevenção e resolução da COVID-19, mostram casos potenciais de efeitos adversos e toxicidade pelo seu uso regular, podendo ter risco de um efeito ampliado por meio de interações medicamentosas, principalmente, relacionado a 
automedicação. Portanto, mais estudos clínicos são necessários para investigar e confirmar a eficácia do seu uso como tratamento antiviral e de seus critérios de administração, para que seja possível comprovar seus benefícios contra a doença.

\section{REFERÊNCIAS}

ASHOUR, Dalia S. Ivermectin: From theory to clinical application. International Journal of Antimicrobial Agents, Egypt, v. 54, ed. 2, 7 maio 2019.

BANERJEE, Kushal et al. The Battle against COVID 19 Pandemic: What we Need to Know Before we "Test Fire" Ivermectin. Thieme E-Journals, India, v. 70, ed. 8, p. 337340, 19 jun. 2020.

BARACCO, Arianna Portmann; ALBERTI, Mayte Bryce; ACCINELLI, Roberto Alfonso. Propiedades antivirales y antiinflamatorias de ivermectina y su potencial uso en COVID-19. Archivos de Bronconeulogía, España, 11 jun. 2020.

CASTRO, José López et al. COVID-19 y Argumentum ad ignorantiam o no todo vale. Revista Clinica Espanola, [s. I.], 25 abr. 2020.

CHANDLER, Rebecca E. Serious Neurological Adverse Events after Ivermectin: Do They Occur beyond the Indication of Onchocerciasis?. The American Journal of Tropical Medicine and Hygiene, [s. I.], v. 98, ed. 2, p. 382-388, 4 dez. 2017.

DIRECCIÓN DE EVALUACIÓN DE TECNOLOGÍAS PARA LA SALUD (México). Gobierno de México. Perspectivas de Tratamiento para COVID-19. México: Secretaria de Salud, 19 jun. 2020. Disponível em: http://docs.bvsalud.org/biblioref/2020/07/1104209/nota_informativa_medicamentos_ mexico_vf.pdf. Acesso em: 1 jul. 2020.

DUTHALER, Urs; SUENDERHAUF, Claudia; KARLSSON, Mats O; HUSSNER, Janine. Population pharmacokinetics of oral ivermectin in venous plasma and dried blood spots in healthy volunteers. British Journal of Clinical Pharmacology, [s. I.], v. 85 , ed. 3, 19 dez. 2018. 
GOWTHAM, Saravanan; KARTHIKEYAN, Kaliaperumal. Wonder Drug for Worms: A Review of three decades of ivermectin use in dermatology. Indian Journal of Dermatology, Venereology and Leprology, [s. I.], v. 85, ed. 6, 11 out. 2019.

INSTITUTO DE EFECTIVIDAD CLINICA Y SANITARIA. Documento de Evaluación de Tecnologías Sanitarias: Informe de Respuesta Rapida. Argentina, 17 jun. 2020. Disponível em: http://docs.bvsalud.org/biblioref/2020/08/1116503/iecs-irr-779ivermectina.pdf. Acesso em: 1 jul. 2020.

LIMA, Alessandra; VIEIRA, Luciana. Kit COVID-19. Brasil: Subsecretaria de Saúde Núcleo de Evidências, 10 jul. 2020. Disponível em: http://docs.bvsalud.org/biblioref/2020/08/1116448/kit-covid-19.pdf. Acesso em: 1 jul. 2020.

MARRA, Lays Pires et al. Ivermectina para COVID-10: Revisão Sistemática Rápida. Hospital Sírio Libanês, Brasil, p. 1-24, 6 maio 2020.

MINISTÉRIO DA SAÚDE. Governo do Brasil. Informe Diário de Evidências COVID19. 45. ed. Brasil, 4 jun. 2020. Disponível em: https://portalarquivos.saude.gov.br/images/pdf/2020/June/05/N45-InformeDiarioreferente-05-06.pdf. Acesso em: 1 jul. 2020.

MINISTÉRIO DA SAÚDE. Governo do Brasil. Informe Diário de Evidências COVID19. 26. ed. Brasil, 8 maio 2020. Disponível em: https://portalarquivos.saude.gov.br/images/pdf/2020/May/11//nformeDiario-referente11-05.pdf. Acesso em: 1 jul. 2020.

SEGURO SOCIAL DE SALUD. Instituto de Evaluación de Tecnologías en Salud e Investigación. Uso de Ivermectina para el Tratamiento de Pacientes Adultos con COVID-19. 2. ed. [S. I.], 8 maio 2020. Disponível em: http://docs.bvsalud.org/biblioref/2020/05/1096653/rb-no-17-v-02ivermectinav209mayo.pdf. Acesso em: 1 jul. 2020. 
SEGURO SOCIAL DE SALUD. Instituto de Evaluación de Tecnologías en Salud e Investigación. Uso de Ivermectina para el Tratamiento de Pacientes Adultos con COVID-19. 17. ed. [S. l.], 9 abr. 2020. Disponível em: http://docs.bvsalud.org/biblioref/2020/05/1096344/rb-17-ivermectina9042020ffreveditado-13420.pdf. Acesso em: 1 jul. 2020.

SINGHASIVANON, On-uma et al. Prevalence and Alternative Treatment of Head-Lice Infestation in Rural Thailand: A Community-Based Study. The Korean Journal of Parasitology, Thailand, v. 57, ed. 5, 31 out. 2019.

WORLD HEALTH ORGANIZATION. Pan American Health Organization. Recommendation Regarding the Use of Ivermectin as a Treatment for COVID-19. America: Pan American Health Organization, 22 jun. 2020. Disponível em: http://docs.bvsalud.org/biblioref/2020/07/1100598/pahoimscdecovid19200033_eng.pdf. Acesso em: 1 jul. 2020.

Enviado: Setembro, 2020.

Aprovado: Outubro, 2020. 